\title{
The Interaction of Morphological Gender With Stereotypical Information: An Eye Tracking Study on Gender Inferences
}

\author{
Daniela Ronca \\ University of Siena \\ DISPOC - Via Roma 56 San Niccolò, 53100 Siena, Italy \\ Vincenzo Moscati (Corresponding author) \\ University of Siena \\ DISPOC - Via Roma 56 San Niccolò, 53100 Siena, Italy \\ E-mail: moscati@unisi.it
}

Received: July 29, 2019

Accepted: August 20, 2019

Published: August 26, 2019

doi:10.5296/ijl.v11i4.15169

URL: https://doi.org/10.5296/ijl.v11i4.15169

\begin{abstract}
In this paper we observe the time-course and the activation of gender stereotypes comparing the predictions of two competing models: the Minimalist (McKoon et al., 1992) and the Mental Model Hypothesis (Garnham 2001). The on-line processing of sentences containing male-biased stereotypes is experimentally investigated in Italian on epicenes nouns (i.e. nouns that do not morphologically disambiguate between male and female referents) adopting a procedure based on the Visual World paradigm.

Eye-movements during sentence comprehension show that stereotypes become immediately active as soon as male-biased role nouns are encountered, as predicted by the Mental Model Hypothesis. Our results also show that when disambiguating cues based on morphological agreement are provided, the activation of stereotypes is blocked. This indicates that morphological gender is quickly processed and that it can suppress stereotypical gender biases.
\end{abstract}

Keywords: Stereotypes, Eye tracking, Morphology, Role nouns, Stereotype suppression, Grammatical gender, Visual world paradigm 


\section{Introduction}

Sentence comprehension is an incremental process, during which incoming elements are quickly integrated in the current representation. This integration works at various levels. For example, processes of reanalysis, including traditional garden-path effects (Frazier, 1987) are well-documented when a word does not fit in the syntactic representation currently being built by the parser. However, incoming linguistic material must not only be compatible with the selected syntactic representation, but they must also be consistent with other types of constraints. Parsing models based on parallel processing (Spivy and Tanenhaus1998; Van Gompel et al. 2000, a.o.) have traditionally focused on the competition or the facilitation effects that various types of information have on sentence processing.

An interesting question concerns the extent to which world-knowledge may trigger automatic inferences that exceed what is explicitly conveyed by the linguistic information. Consider gender. In this domain a clear distinction exists between grammatical and biological gender and a mismatch between the two may arise. In Italian, for example, a class of "epicenes" nouns have a lexically specified gender that could mismatch the biological gender. To mention one, the noun "vittima", i.e. "victim", is grammatically marked as feminine but it may nevertheless refer to a man.

A way to investigate the interaction between linguistic representations and other domains of cognition is to observe how gender stereotypes, which are based on our past experience, interact with the linguistic representations built through the parsing of gender morphology. This kind of stereotype is particularly evident with role nouns. For example, the association between "soldier" and "man" is not conveyed by morphological gender, but it is nevertheless strongly rooted in the social environment of most cultures.

The consensus on the fact that stereotypes can be activated during language processing and that they can play a role in communication (Banaji et al., 1996) is widespread. However, the exact nature of their activation, their alleged automaticity, and their interaction with morpho-syntactic traits are still controversial issues. In this paper we aim at observing the activation of stereotypes linked to role nouns, and the influence that additional morphological information may have in blocking them. We will focus here on Italian, a language whose rich inflectional morphology allows to control for grammatical gender. In particular, we will explore the on-line processing of bi-clausal sentences in which morphosyntactic information can be used to disambiguate the biological gender of a following role noun. To illustrate, consider the following minimal pairs:

$\begin{array}{rllllll}\text { (1) } \underline{\text { Essendo }} & \text { ingegnere, } & \text { si } & \text { era } & \text { comprata } & \text { un nuovo studio in città. } \\ \text { Be-GER } & \text { engineer } & \text { REFL } & \text { be-PST } & \text { bought-PST.F a new study in town. }\end{array}$

'Being an engineer, she bought herself a new study in town.'

(2) Diventata ingegnere, si era comprata un nuovo studio in città. Be-PTCP.F engineer REFL be-PST bought-PST.F new study in town.

'When she became an engineer, she bought herself a new study in town.' 
In the sentences above, the first clause is a reduced clause with a gerund (1) or a past participle (2) followed by a role noun. In Italian, only past participles carry gender agreement (diventat- $a_{\text {fem }}$ /diventat-o $o_{\text {masc }}$ ): while (2) disambiguates the gender of the following role noun, (1) leaves its gender unspecified. The contrast between (1) and (2) may thus be exploited to observe the automatic activation of stereotypical gender, that should be visible in (1) and the blocking effect that the morphological traits in (2) may have in preventing unwarranted gender inferences.

The paper is structured as follows: in the next section we will briefly summarize existing literature and the different predictions stemming from two opposed accounts, the "Mental Model" and the "Minimalist Hypothesis". Then we will present the design and the results of a novel eye-tracking experiment based on the Visual World paradigm (Cooper, 1974; Tanenhaus et al., 1995; Moscati et al., 2017). Finally, we discuss how our results support the "Mental Model Hypothesis" and the view that gender inferences are automatically generated, unless blocked by disambiguating morphology, as in sentences like (2).

\section{Gender Inferences and Representational Models}

Previous research on stereotypes' activation has focused on their contribution to the automatic formation of coherent representational models, looking at sentence processing and at the slow-downs that can be registered whenever a mismatch between morphosyntactic gender and stereotypical gender occurs. The role played by extra-linguistic inferences and their automaticity during sentence comprehension has been central in a lively debate on representational models' formation, opposing at least two different views (see Kreiner et al., 2008 , for a critical overview) that we present here.

According to the "Minimalist Hypothesis" proposed by McKoon et al., (1992), the number of inferences made during sentence processing is kept to a minimum: only what is strictly necessary to make sense of the current utterance is generated. Additional inferences, including those based on gender stereotypes, are not obligatory and are suspended until needed. This would allow a saving in terms of computational resources, as the representation is finalised with minimal efforts. In this view, since role nouns may be left morphologically unmarked for gender, they do not generate any further inference.

In contrast to the "Minimalist Hypothesis", a second hypothesis may be traced back to Garnham's (2001) "Mental Model Hypothesis”, which assumes that representational models are not only built on explicit linguistic information, but that they are also enriched by world knowledge. World-knowledge inferences are automatic, and their activation becomes visible whenever a clash between morphological and stereotypical gender occurs (Carreiras et al., 1996; Cacciari et al., 1997; a.o.). The clash is quickly solved, since the weight of syntactic information is greater, but a slowdown in reaction times is indicative of the activation of gender stereotypes. Previous research (Pyykkönnen et al, 2010; Siyanova-Chanturia et al. 2015) indicated that stereotypes may be activated also when role nouns are presented in isolation (see Banaji et al.,1996; Osterhout et al., 1997, for a "lexicalist" version of the "Mental Model Hypothesis", in which stereotypes are not seen as automatic inferences, but directly encoded in the lexicon. See also Kreiner et al., 2008 for evidence against the 


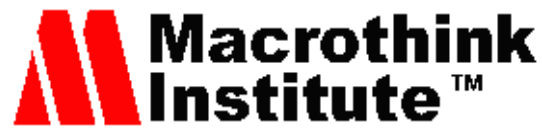

International Journal of Linguistics

ISSN 1948-5425

"lexicalist" view). In this debate, the observation of processing differences between sentences like (1) and (2) in Italian may provide further evidence to test the predictions of the "Minimalist" and the "Mental Model hypothesis". In fact, they clearly diverge on the expected modality in which the first clause of both sentences is going to be processed. According to the "Minimalist Hypothesis", the first clause of sentence (1) "essendo ingegnere", i.e. "being engineer", should not trigger any stereotype activation, since neither the gerund nor the role noun encode gender information. On the other hand, according to the "Mental Model Hypothesis", gender stereotypes become activated as soon as possible (Reynolds et al., 2006) and the word "engineer" in the first clause of (1) should create an articulated representational model in which it refers to a male referent. This should happen even in absence of explicit gender information.

A way to test these predictions is through the Visual World paradigm: if stereotypical gender is activated in absence of morphological information, as claimed by the Mental Model Hypothesis, in sentences like (1) we would expect more fixations toward a male referent than toward a female competitor.

Notice that adopting the Visual World paradigm, we may be able to observe the activation of stereotypes without introducing gender mismatches as previous studies did. This is an important methodological difference. In fact, the online activation of stereotypes was previously investigated using reading times or reaction times, assuming that a mismatch between morphological and stereotypical gender would cause a slow down. An example is the study described in Carreiras et al. (1996) in which reaction times were compared while reading sentences that could contain a morphology/stereotype mismatch as in " $l a_{f e m}$

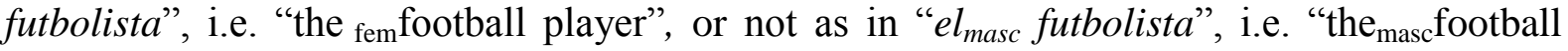
player". In Spanish, as in most Romance languages, the determiner can encode gender agreement with the noun and it can be either masculine "el" or feminine "la". Thus, a mismatch between the gender of the definite article and the (stereotypical) gender of following noun could cause a clash, indirectly showing the activation of gender stereotypes associated with "footbolista". Differently from Carreiras (et al., 1996) we used sentences like (1) that contain no mismatch in the first clause. Here stereotype activation could be detected not by registering slowdowns in reading, but more directly by looking at the proportion of eye-gazes directed toward a male referent.

Beside this methodological point, the contrast between (1) and (2) would also determine whether agreement morphology on the verb is able to override the activation of gender stereotypes. Garnham and Yakovlev (2015) found that in Russian "grammatical gender marking on predicates (verbs) was not immediately and completely used to counteract stereotype information". In our study, we employed verbal agreement on a past participle: if this type of grammatical gender marking is weak, we expect that it should not be able to override stereotypes, also in Italian. On the contrary, if an effect is observed, this would suggest that the Visual World paradigm is a more sensitive methodology than reaction-time detection. 


\section{Experiment}

In order to investigate the real-time activation of gender stereotypes, we designed a new experiment employing bi-clausal sentences in which the first clause was manipulated as to either contain disambiguating morphological information, or not. More specifically, the first clause served as a temporal adjunct and the lexical verb was either a past participial form that carries gender and number agreement, or an invariant gerund. To illustrate, consider first the initial clause containing the past participle. Sentence (2) is again repeated in (5) below:

(5) Diventata ingegnere, si era comprata un nuovo studio in città.

CLAUSE1 $_{[}\left[\right.$diventata $\left[\right.$SG.F] ingegnere $\left.\operatorname{pro}_{[\mathrm{SG} . \mathrm{F}]}\right]$

${\text { CLAUSE2 } 2 \text { pro }_{[S G . F] i} \text { si era comprata }}_{[S G . F]}$ un nuovo studio in città]

Clause 1 serves as a temporal adjunct (see Belletti, 1992) in which the subject may be realized by a silent pronoun indicated as pro (Rizzi, 1982). Since the past-participle agrees with the subject in number and - more importantly - with gender, the null pronoun receives feminine and singular syntactic traits, overriding the stereotypical gender eventually associated with the role noun. Therefore, a new singular and feminine referent, with the property of being an engineer, is introduced in the discourse.

Discourse cohesion (Marslene-Wilson, 1982) and the costs associated with the introduction of new referents (Crain \& Steedman, 1985) will ensure that the same referent is maintained constant once the main clause is later encountered. When the second clause is encountered, the most natural interpretation is the one in which its subject is the same of the previous clause: the feminine referent already introduced. We used the same index $i$ to indicate co-reference. In the main clause, the second past participle "comprata ${ }_{[\mathrm{SG} . \mathrm{F}]}$ " "bought" also bears gender agreement, adding coherent information about the gender (feminine) of the referent. Therefore, no reanalysis is expected.

Let's now consider sentences in which no early disambiguation occurs. Consider again sentence (1), reported again in (6):

(6) Essendo ingegnere, si era comprata un nuovo studio in città.

Clause1 $\left[\right.$ essendo ingegnere pro $_{[-,-] i}$ stereotype=masculine $]$

CLAUSE2 $2_{\text {pro }_{[-,-] i}}$ si era comprata ${ }_{[S G . F]}$ un nuovo studio in città]

In (6) the temporal adjunct is constituted by a gerund clause. Gerunds do not carry morphological specification for number and gender: these traits are thus left underspecified on the subject (morphosyntactic traits in square brackets are left empty): only extralinguistic information could be used to enrich the mental representation, adding inferences about the gender of the subject. In this condition, the effects of stereotypical gender should be maximally visible. Role nouns like "engineer" are expected to be biased toward an association with a male referent. Therefore, we expected here, according to the predictions of the "Mental Model Hypothesis", that a masculine referent will be more active and fixated longer than a female competitor. If activated by a stereotypical inference, the same masculine 
referent will be maintained active also in Clause 2. But this time, if a heuristic based on world knowledge has assigned masculine gender to the pronoun, we also expected a clash and a reanalysis when the feminine grammatical trait is encountered on the past principle of the second clause.

In addition to the position of the first disambiguating participle (Early= clause 1; Late= clause 2), we also manipulated the gender traits on the past participle in the second part of each sentence, that could either be masculine or feminine (e.g. comprat-o masc / comprat-a $\mathrm{f}_{\text {fem }}$ ). Therefore, in one set of conditions, the past participle specification, masculine and singular, was coherent with the stereotyped gender. In the other set, instead, a mismatch was introduced between the masculine stereotype and the feminine traits carried by the disambiguating past participle.

As a preliminary step we carried a preliminary norming study in order to selected role nouns with a strong masculine bias, so to ascertain the gender bias carried by the role nouns that would be later included within the experimental materials.

\subsection{Norming Study}

Seventy role nouns were collected from online resources (Enciclopedia Treccani, 2018), and they were inserted in a simple online form. This initial list contained stereotypes of both female and male gender, for example "nurse" for female and "soldier" for men. Subjects were asked to assign to each role noun a value from one to seven, where the value one corresponded to "male" and seven corresponded to "female". The test was administrated to twenty-nine subjects. They were all Italian L1 speakers at the University of Siena. For each of the seventy role nouns tested, the mean value of the assigned ratings was calculated. Sixteen role nouns had an assigned mean value inferior to three on the scale from one to seven. The smallest value was assigned to "gommista", i.e. someone working in a tire shop, and it was 1.82 . This reveals the fact that "gommista" is strongly stereotyped as being male. The highest value was assigned to "badante", i.e. "caregiver", which obtained 5.58. It was the most female-biased stereotype. Considering the whole list, thirty-two role nouns out of those most associated to a male stereotype were chosen. The ratings assigned to these nouns ranged from 1.82 to 3.44 , obtained respectively by "falegname", i.e. "carpenter", and "preside", i.e. "headmaster". The mean value was 2.95 .

\subsection{Participants}

Twenty subjects participated to the experiment. Sixteen of them were students at the University of Siena. They were thirteen females and seven males. Thirteen participants were undergraduates, four were postgraduates, and the remaining three subjects had an occupation as part-time workers at different workplaces in the university. All participants were native speakers of Italian.

\subsection{Apparatus}

All subjects were tested in our lab with obscured windows to avoid direct light that could interfere with eye-tracking. The artificial light was regulated during the test phase so to 


\section{Ml Macrothink}

International Journal of Linguistics

ISSN 1948-5425

2019, Vol. 11, No. 4

obtain optimal lighting conditions. Eye movements were recorded through a Tobii Pro X2-60 eye tracker, set to a sampling rate of $10 \mathrm{~Hz}$. The eye tracker was mounted right below the 15-inches display of a Notebook PC with an AMD-A8-4555M CPU and with a Radeon HD Graphics $1.60 \mathrm{GHz}$ processor. The experiment was built with OpenSesame v3.2.1 (www.osdoc.cogsci.nl).

\subsection{Procedure}

Subjects sat comfortably in front of the laptop and the eye-tracker was calibrated via a standard 5 points procedure. Immediately after, they read the instructions on the screen and started a short familiarization sequence in which they heard four sentences while looking at pictures. Pictures in this familiarization phase were arranged as to be similar to the successive test session.

\subsection{Method and Materials}

We had 4 experimental conditions. The first manipulation concerned the lexical verb of the first clause, that could either contain a past participle with gender agreement (diventat- $o_{\text {masc }}$ $/-a_{\mathrm{fem}}$ ingegnere $)$ or a gerundive verb without gender information (essendo ingegnere). In addition, we also manipulated the morphological gender of the participle in the second clause, using either the masculine or the feminine (comprat- $o_{\text {masd }}-a_{\text {fem }}$ ). In all conditions, we used fully grammatical sentences. The experimental design was a 2 (Disambiguation: Early, Late) x 2 (Morphological Gender: Feminine, Masculine) within-subject design. The four experimental conditions are exemplified in Table 1:

Table 1. Examples of the four experimental conditions, determined by disambiguation (early, late) and morphological gender (feminine, masculine)

Condition

Clause 1

Clause 2

$0-1500 \mathrm{msec}$

Disambiguation Continuation

$1501-2500 \mathrm{msec} \quad 2501-4500 \mathrm{msec}$

\begin{tabular}{llll} 
early, masculine & diventato ingegnere & si era comprato & un nuovo studio in città \\
\hline early, feminine & diventata ingegnere & si era comprata & un nuovo studio in città \\
\hline late, masculine & essendo ingegnere & si era comprato & un nuovo studio in città \\
\hline late, feminine & essendo ingegnere & si era comprata & un nuovo studio in città
\end{tabular}

Sentences were inspected via an audio editing software (www.audacityteam.org) and aligned so that Clause 1 duration was $1500 \mathrm{msec}$, the disambiguating part of clause 2 lasted 1000 msec and the continuation at most $2000 \mathrm{msec}$. 


\section{Macrothink}

The 32 role nouns that received the highest score as masculine stereotypes in the preliminary norming study were used in each condition, thus having a set of 128 sentences. These sentences were then assigned to four lists, and subjects were randomly assigned to each list. In this way, each subject heard the same role noun only once, with 8 sentences for each condition in Table 1. We also added 32 sentences with a gender-unambiguous nouns carrying gender morphology (fotograf-o $o_{\text {mas }} /$ fotograf- $a_{\text {fem }}$ ) and 40 fillers. Each subject was presented with a total of 104 sentences, divided into four blocks, in a random presentation order.

While hearing the target sentence, a picture appeared on screen. The four corners of the screen were occupied by four images: two of them depicted persons of different biological sex. They could either be the target or the distractor, depending on the past participles' morphology. The other two pictures, the distractors, were an animal (e.g. a flamingo) and an inanimate object (e.g. a cactus). Each picture was associated with a different ROI: a male picture appeared in ROI1, a female picture in ROI2, an animal in ROI3, and an inanimate object in ROI4. An example of the visual display is given in figure 1 below. The four ROIs were randomly shuffled in each trial.

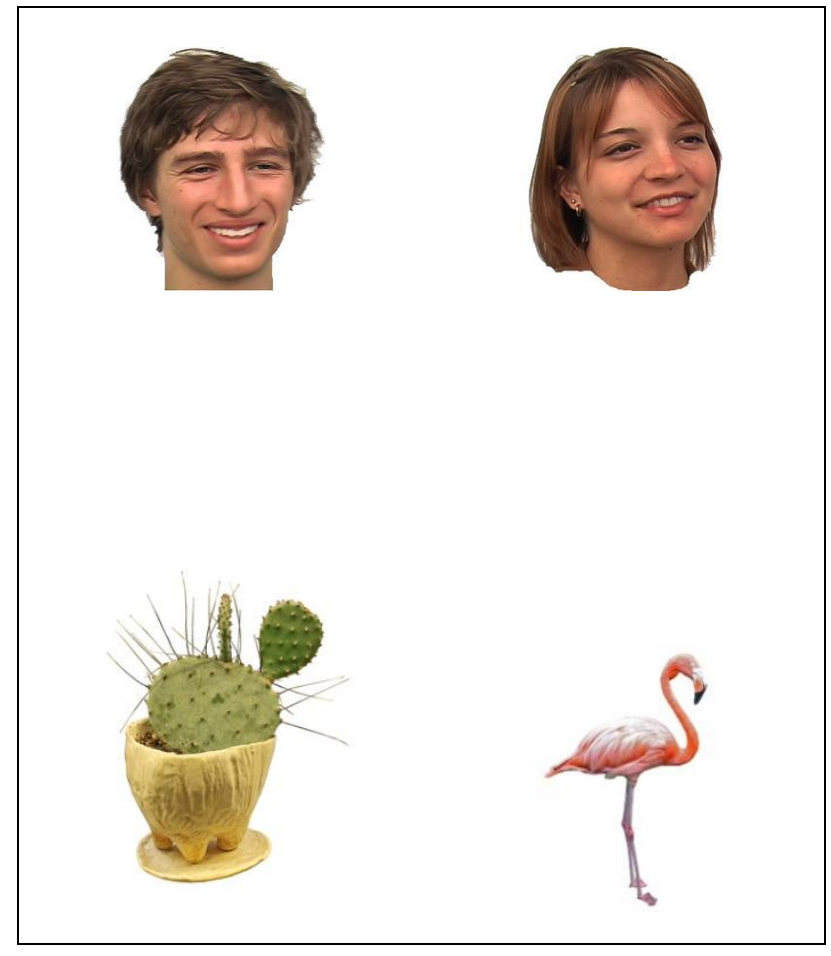

Figure 1. Example of the visual display used in the visual world

After the picture appeared on screen, the target sentence started with a 1 sec. delay. Eye-movements were recorded from the beginning of the trial, i.e. from the appearance of the picture on the screen.

\subsection{Data Preparation}

We sampled eye-gaze with a frequency of $10 \mathrm{HZ}$, thus collecting a maximum of 10 fixations per second, one each $100 \mathrm{msec}$, for 6 seconds. In total we had 60 time-slices. Data were 
prepared using the $\mathrm{r}$ package eye-tracking $\mathrm{R}$ (Dink et al., 2015). Track losses and fixations outside one of the four ROIs were excluded.

\subsection{Results}

In order to determine how stereotypical gender inferences interacted with the morphological traits carried by the past participle, we looked at the proportion of fixations to the correct referent depending on the point (Early vs Late) of morpho-syntactic disambiguation. The proportion of fixations on target are reported in Figure 2. In the Masculine conditions (left panel) the target was in ROI1 (male picture) while in the Feminine Conditions (right panel) it was in ROI2 (female picture).

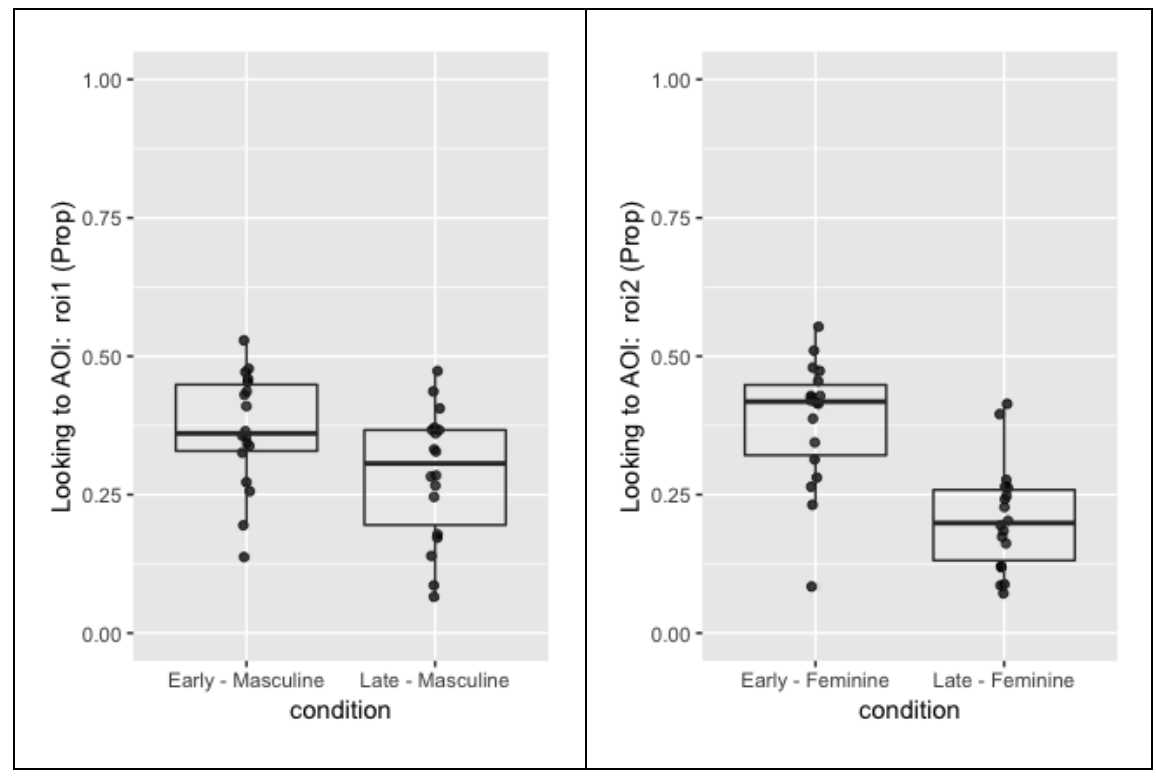

Figure 2. Overall proportion of fixations to the target referent. Left Panel: proportion of fixations in ROI1 (male picture) for the Masculine Early/Late conditions. Right Panel: proportion of fixations in ROI2 (female picture) for the Feminine Early/Late conditions.

In the Masculine conditions (Fig2, left), the proportion of fixations in ROI1 was higher in the Early $(M=36.7, S D=10.4)$ than in the Late condition $(M=28.7, S D=11.8)$. This difference was significant $(\mathrm{p}<.001)$ as revealed by modelling the data using a mixed effect model with condition (Early vs Late) as predictor and the Logit transformed proportion of fixations at ROI1 as the dependent variable. Subjects and Items were included as random effects.

The same general pattern was found also in the Feminine conditions, where again the proportion of fixations to the female picture in ROI2 was higher in the Early $(\mathrm{M}=38.4, \mathrm{SD}=$ 11.4) than in the Late condition $(\mathrm{M}=20.7, \mathrm{SD}=9.6)$. This difference was also significant $(\mathrm{P}<.001)$, as confirmed by using a model similar to the previous one but this time using the Logit transformed proportion of fixations at ROI2.

Figure 2 also shows that, while the proportion of fixations to the target in the Early conditions is very similar for masculine and the feminine sentences, the Feminine Late condition presents a lower proportion of fixations on target $(M=20.7)$ when compared to the Masculine Late Condition $(\mathrm{M}=28.7)$. This suggests that, if feminine morphology is encountered later, 
subjects tend to look more and longer at the picture of the man. This is indeed the case, as shown by plotting the proportion of fixations on target while the sentence unfolds in time (Figure 3). We plotted time-bins of $300 \mathrm{msec}$, aggregating 3 data-points together. To help matching eye-gazes with the linguistic stimuli, in Figure 3 we marked the sentence time-course using the same partition used in Table 1.
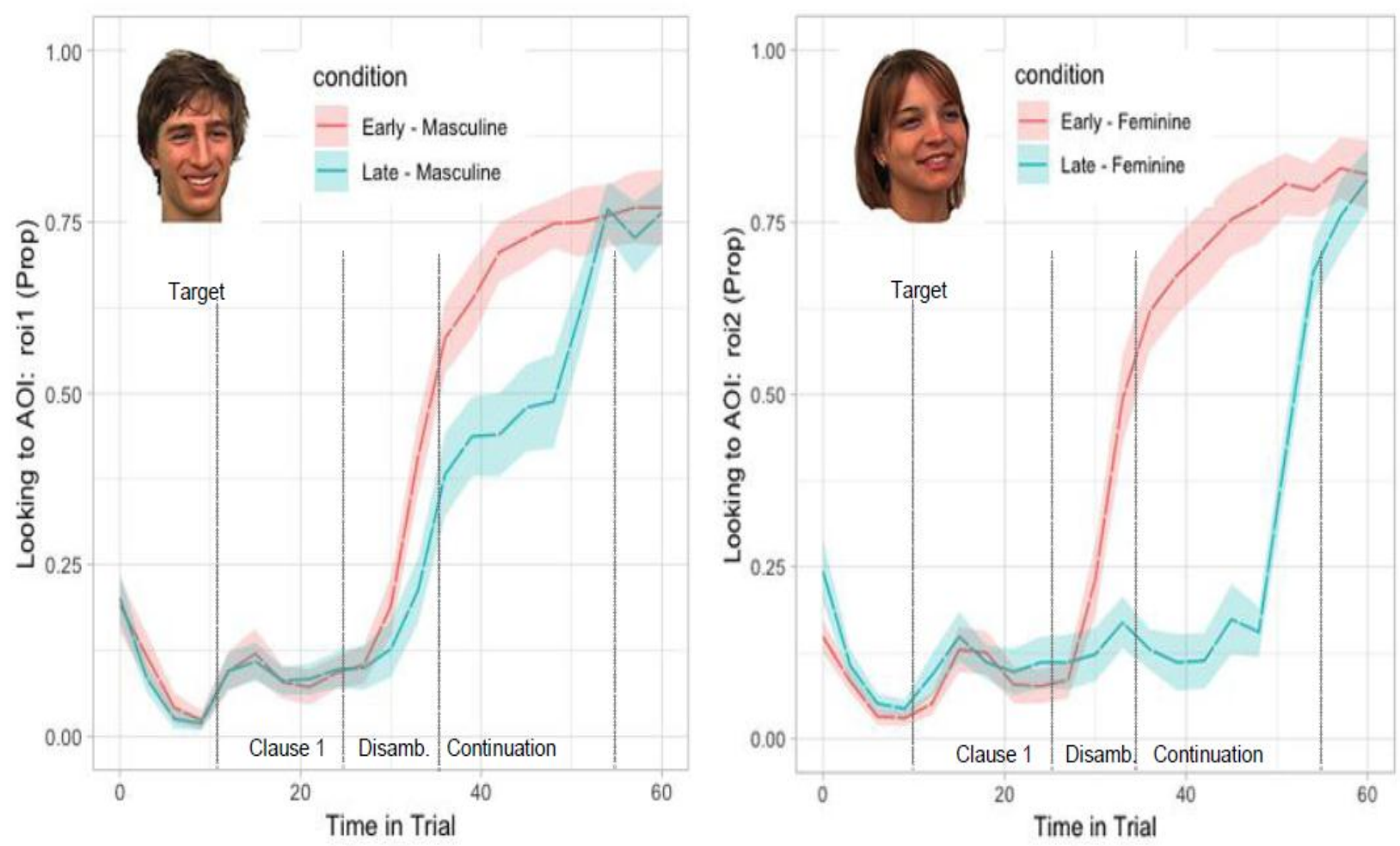

Figure 3. Proportion of fixations toward the target referent. Left Panel: time-course of proportion of fixations in the ROI1 (Male), the target region for the Masculine Early/Late conditions. Right Panel: time-course of proportion of fixations in the ROI2 (Female), the target region for the Feminine Early/Late conditions.

Figure 3 shows that the proportion of fixations to the correct referent seems to grow at the same time, both in the Early-Masculine than in the Early- Feminine condition, namely soon after Clause 1. To verify this observation, we determined the cluster(s) in which the proportion of fixations on target diverged, becoming significantly higher for the Early conditions. To do so, we ran two separate cluster-based permutation analysis (Maris et Oostenveld 2007), one for the Masculine and one for the Feminine conditions. The analysis identifies potential clusters joining together adjacent bins that surpassed a $t$ threshold of $\alpha=.05$. For the male condition, the analysis revealed that the proportion of fixation to the male referent diverged in clusters 30-54, p.<0.001, while for the female condition, it revealed a divergence from clusters $30-57$, p. $<0.001$. 


\section{MInstitute Macrothink $_{\text {Int }}$}

International Journal of Linguistics

ISSN 1948-5425

Table 2. Summary of the cluster-based permutation analysis. Start and End time reporting temporal bin's number and its probability to look at the target different form a random bin sampling

\begin{tabular}{lccc}
\hline \multicolumn{1}{c}{ Condition } & $\begin{array}{c}\text { Cluster } \\
\text { Start Time }\end{array}$ & $\begin{array}{c}\text { Cluster } \\
\text { End Time }\end{array}$ & $\begin{array}{c}\text { Probability of } \\
\text { looking at Target }\end{array}$ \\
\hline Early Masculine Vs Late Masculine & 30 & 54 & $\mathrm{p}<0.001$ \\
\hline Early Feminine Vs Late Feminine & 30 & 57 & $\mathrm{p}<0.001$ \\
\hline
\end{tabular}

Table 2 shows that morphological info is used at the same time in the Feminine and in the Masculine conditions, directing eye gazes toward the correct referent at time bin 30, quickly overriding gender stereotypes. However, a difference is found in the Late conditions: it takes longer in the Late Feminine condition to look at the female picture (Bin 57) than in the Late Masculine condition to look at the male picture (Bin 54). The cluster-based permutation analysis revealed a delay of 3 time-bins, corresponding to a $900 \mathrm{msec}$ delay.

To fully appreciate the role of gender inferences, we inspected again our data, but this time using as the dependent variable the proportion of fixations to the competitor, instead of the target. For the Feminine condition, the competitor is the man in ROI1, i.e. the picture that should be associated with a gender stereotype. Conversely, for the Masculine condition, the competitor is the female in ROI2. Since we only chose role nouns biased toward a male referent, we did not expect that the female competitor in ROI2 would become active. We report the proportion of fixations to the competitor (Figure 4). For the Masculine condition (left panel) the competitor is in ROI2 (female picture), while for the Feminine Condition (right panel) it is in ROI1 (male picture).

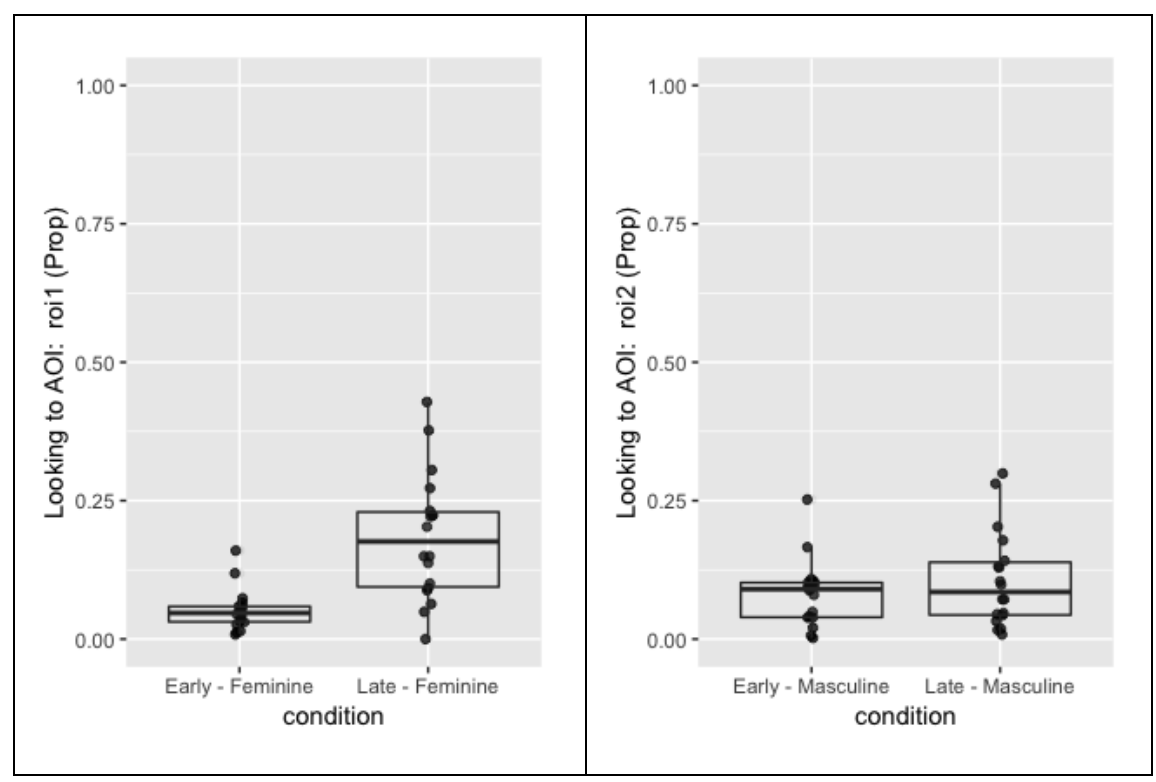

Figure 4. Overall proportion of fixations to the competitor. Left Panel: proportion of fixations in ROI2 (female picture) for the Masculine Early/Late conditions. Right Panel: proportion of fixations in ROI1 (male picture) for the Feminine Early/Late conditions. 


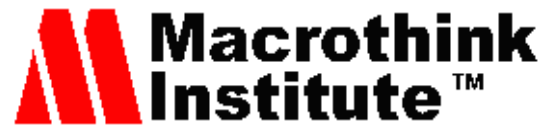

In the Masculine conditions (Fig4, left), the proportion of fixations to the female competitor in ROI2 was slightly higher in the Late $(\mathrm{M}=10.7, \mathrm{SD}=8.7)$ than in the Early condition $(\mathrm{M}=8.2, \mathrm{SD}=6.0)$. This difference was nonsignificant as determined by running a mixed effect model with condition (Early vs Late) as predictor, subjects and items as random effects and the Logit transformed proportion of fixations at ROI2 as the dependent variable. This confirmed that the female referent is not activated in the Masculine conditions.

In the Feminine conditions, a greater difference in the proportion of fixations to the competitor is found depending on whether the feminine morphology in provided Early $(\mathrm{M}=5.2, \mathrm{SD}=3.7)$ or Late $(\mathrm{M}=18.4, \mathrm{SD}=11.4)$. The difference is highly significant $(\mathrm{P}<0.001)$. This shows that masculine gender stereotypes are very active in absence of morphological information. The tendency to look at the man's picture holds unless contrary morphological information is explicitly provided. This becomes clearly visible once fixations to the competitor are plotted in time (Figure 5)
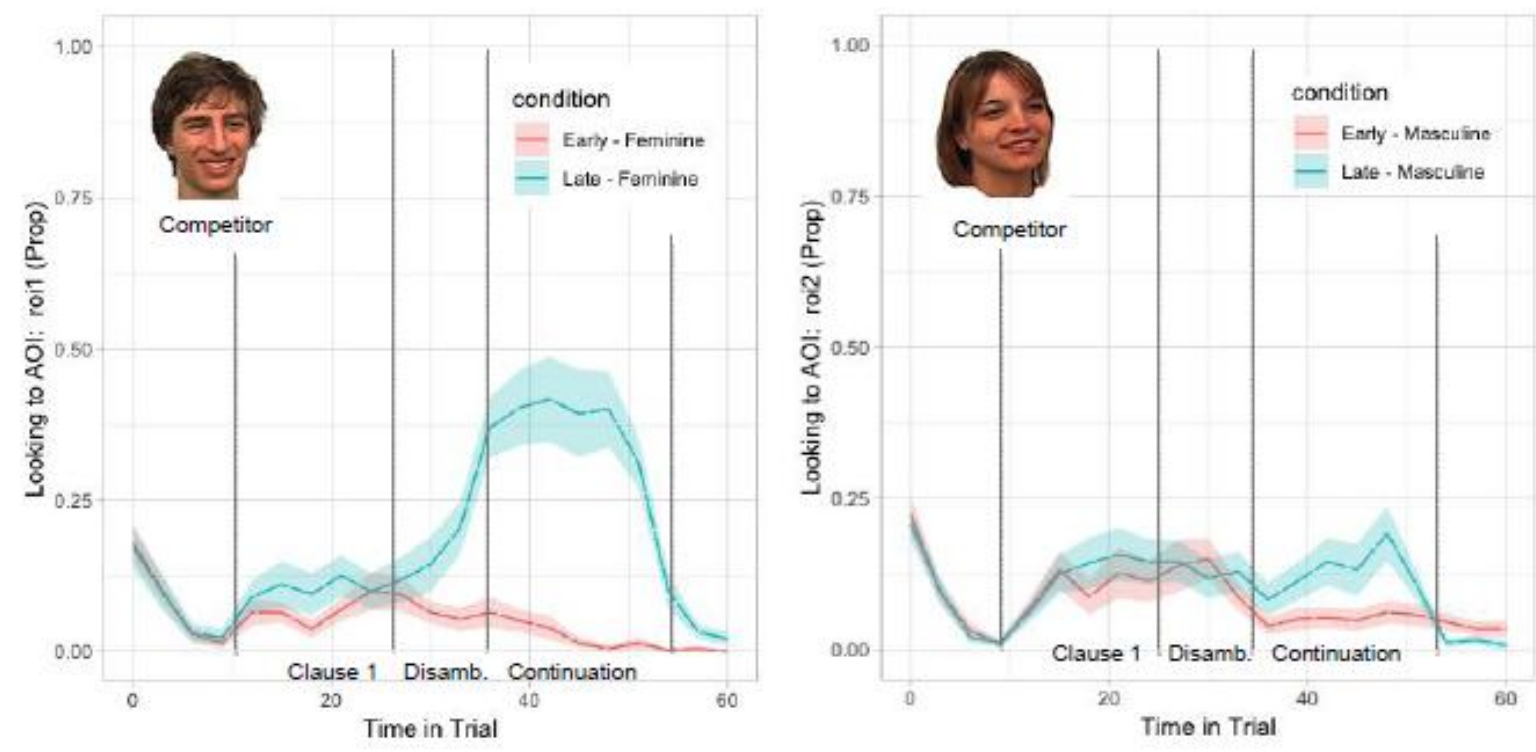

Figure 5. Proportion of fixations toward the Competitor. Left panel: time-course of proportion of fixations in the ROI1 (Male), the competitor region for the Feminine Early/Late conditions. Righty Panel: time-course of proportion of fixations in the ROI2 (Female), the competitor region for the Masculine Early/Late conditions.

Again, we ran two separate cluster-based permutation analysis. For the Male Condition, the analysis revealed that the proportion of fixations to the female referent only diverged in clusters 39-45, p. $<0.05$. For the Feminine condition, instead, two different clusters were isolated: the first between bins 18-24 ( $<<0.05)$ and the second between bins 33-57 ( $<<0.001)$. 
Table 3. Summary of the cluster-based permutation analysis. Start and End time reporting temporal bin's number and its probability to look at the distractor different form a random bin sampling

\begin{tabular}{lccc}
\hline Conditions & $\begin{array}{c}\text { Cluster } \\
\text { Start Time }\end{array}$ & $\begin{array}{c}\text { Cluster } \\
\text { End Time }\end{array}$ & $\begin{array}{c}\text { Probability of looking } \\
\text { at the Competitor }\end{array}$ \\
\hline Early Masculine Vs Late Masculine & 39 & 45 & $\mathrm{p}<0.05$ \\
\hline Early Feminine Vs Late Feminine & 18 & 24 & $\mathrm{p}<0.05$ \\
\hline Early Feminine Vs Late Feminine & 33 & 57 & $\mathrm{p}<0.001$ \\
\hline
\end{tabular}

The cluster-based permutation analysis show that a male referent becomes active as soon as the role noun is encountered (bins 18-24) and it is still active until late, well after late morphological information has been encountered (bins 33-57). As for the female competitors, they are only briefly activated (bin 39-45) when no male morphology is encountered.

\section{Conclusions}

The first result of our experiment is that in the Feminine Late condition, a stereotyped gender inference is quickly made, as the proportion of fixations toward a male referent shows. This inference starts as soon as the role noun is encountered, and it lasts until the feminine past participle in the second clause is met. This pattern is predicted by the "Mental Model Hypothesis", since the mental model of the hearer is enriched by extra-linguistic information.

A second result concerns the difference between the proportion of fixations on the target, depending on when the disambiguating morphology carried by the past participle is introduced. This is particularly evident in the Feminine condition. In fact, when a feminine past participle is provided before the role noun, it swiftly blocks gender inferences. This result is similar to Carreiras' (et al., 1996) study on Spanish. Linguistic information can thus quickly and completely override gender inference. This indicates that the hearers' representational model can indeed be completed with different sources of world-knowledge, but only if this addition is compatible with the explicit grammatical information.

It is also worth to point out that the effect of morphology, in this case gender on past participle, is strongly significant and similar to Carreiras et al, in which feminine morphology was carried by the definite article. In contrast, Garnham and Yakoview (2015) reported that the effect of morphological information in Russian is weak and unable to completely override stereotypical gender. It is possible that this difference is due to some language-specific difference between the Italian and Russian. However, it can also due to the different tasks that have been used, with the Visual World being more sensitive to detect the effect of morphology. 


\section{Macrothink}

\section{References}

Banaji, M. R., \& Hardin, C. D. (1996). Automatic stereotyping. Psychological Science, 7, 136-141.

Belletti, A. (1992). Agreement and case in past participle clauses in Italian. Syntax and semantics, 26, 21-44.

Cacciari, C., Carreiras, M., \& Cionini, C. B. (1997). When Words Have Two Genders: Anaphor Resolution for Italian Functionally Ambiguous Words. Journal of memory and language, 37, 517-532.

Carreiras, M., Garnham, A., Oakhill, J., \& Cain, K. (1996). The Use of Stereotypical Gender Information in Constructing a Mental Model: Evidence from English and Spanish. The Quarterly Journal of experimental psychology. 49A, 639-663.

Cooper, R. M. (1974). The control of eye fixation by the meaning of spoken language: A new methodology for the real-time investigation of speech perception, memory, and language processing. Cognitive Psychology, 6(1), 84-107.

Crain, S., \& Steedman, M. (1985). On not being led up the garden path: The use of context by the psychological syntax processor. In D.R. Dowty, L. Karttunen, \& A.M. Zwicky (Eds.), Natural Language Parsing: Psychological, Computational and Theoretical perspectives (pp. 320-358). Cambridge, England: CUP.

Enciclopedia Treccani. (2018). Parole ambigeneri. Retrieved January 10, 2018, from http://www.treccani.it/enciclopedia/parole-ambigeneri_\%28Enciclopedia-dell\%27Italiano\%2 9/

Frazier, L. (1987). Sentence processing: A tutorial review. In M. Coltheart (Ed.), Attention and performance XII. Hillsdale, NJ: Lawrence Erlbaum Assoc.

Garnham, A., \& Yakovlev, Y. (2015, November). The interaction of morphological and stereotypical gender information in Russian. Frontiers in Psychology, 6, 1-12.

Garnham, A., (2001). Mental models and the interpretation of anaphora. Hove: Psychology Press.

Kreiner, H., Sturt, P., \& Garrod, S. (2008). Processing definitional and stereotypical gender in reference resolution: evidence from eye-movements. Journal of Memory and Language. 58, 239-261.

Maris, E., Oostenveld, R., (2007). Nonparametric statistical testing of EEG- and MEG-data. Journal of Neuroscience Methods 164 (1), 177-190.

Marslen-Wilson, W., Levy, E., \& Tyler, L. K. (1982). Producing interpretable discourse: the establishment and maintenance of reference. In R. J. Jarvella \& W. Klein (Eds.), Speech, Place and Action. New York: Wiley. 


\section{Macrothink}

International Journal of Linguistics

ISSN 1948-5425

2019, Vol. 11, No. 4

McKoon, G., \& Ratcliff, R. (1992). Inference during reading. Psychological Review, 99, 440-466.

Moscati, V., Zhan, L., \& Zhou, P. (2017). Children's on-line processing of epistemic modals. Journal of Child Language, 44(5), 1025-1040.

Osterhout, L., Bersick, M., \& Mclaughlin. (1997). Brain potentials reflect violations of gender stereotypes. Journal of Memory \& Cognition, 25, 273.

Pyykkönen, P., Hyönä, J., \& van Gompel, R. P. G. (2010). Activating gender stereotypes during online spoken language processing: Evidence from visual world eye tracking. Experimental Psychology, 57(2), 126-133.

Reynolds, D. J., Garnham, A., \& Oakhill, J. (2006). Evidence of immediate activation of gender information from a social role name. The Quarterly Journal of Experimental Psychology, 59(5), 886-903.

Rizzi, L. (1982). Issues in Italian Syntax. Foris Publications, Dordrecht.

Siyanova-Chanturia, A., Warren, P., Pesciarelli, F., \& Cacciari, C. (2015). Gender Stereotypes across the Ages: On-Line Processing in School-Age Children, Young and Older Adults. Frontiers in Psychology, 6.

Spivey, M. J., \& Tanenhaus, M. K. (1998). Syntactic ambiguity resolution in discourse: Modeling the effects of referential context and lexical frequency. Journal of Experimental Psychology: Learning, Memory, and Cognition, 24(6), 1521-1543.

Tanenhaus, M. K., Spivey-Knowlton, M. J., Eberhard, K. M., \& Sedivy, J. C. (1995). Integration of visual and linguistic information in spoken language comprehension. Science, 268(5217), 1632-1634.

Van Gompel, R.P.G., Pickering, M. J., \& Traxler, M. J. (2000). Unrestricted race: A new model of syntactic ambiguity resolution. In A. Kennedy, A. Radach, R. Heller, Dieter, \& J. Pynte (Eds.), Reading as a perceptual process (pp. 621-648).

\section{Copyrights}

Copyright for this article is retained by the author(s), with first publication rights granted to the journal.

This is an open-access article distributed under the terms and conditions of the Creative Commons Attribution license (http://creativecommons.org/licenses/by/4.0/). 